\title{
Science of Music in the Education System of Uzbekistan
}

\author{
Saida Kasymhodjaeva \\ The State Conservatory of Uzbekistan, Tashkent, Uzbekistan
}

\begin{abstract}
Perceiving musicology as a combination of scientific and academic disciplines, and considering the history and the way of its development, the author pays more attention to the problem of understanding the evolution of music and musical science. Music education is presented in the relationship of the two main areas: science and education. There is evidence of a gradual expansion and changes in the content and methods of the science of music. The 21 st century rapidly and dynamically entered in our lives in terms of the development of information communication, technological progress and unprecedented rise of scientific thought. Social upheavals of this period of history, a powerful wave of liberation movements have caused an unprecedented intensification of national creative forces committed to the development, expansion of contacts, attached to the other cultures. To date, the science of music has evolved so much on what grew out of it and separated into clearly separate spheres with their problems, trends, directions: music theory, music history, ethnomusicology, musical philosophy, and also music source studying. And it should be noted that each of these areas has its embodiment in materialized form of faculties, departments in the conservatory. Development of new standards, new plans, programs, new courses is a related process of development of these sciences in general.
\end{abstract}

Keywords: education, science, history, information, technology, modernity, Farabi, Jami

\section{Introduction}

Practical implementation of the above trends - science and education - is closely linked to the education system, since it is the most effective means of spiritual and cultural formation of the younger generation, and stimulates the development of society as a whole. Based on this, we would like not an exhaustive still try to follow the general development of musicology as Humanities, and if possible hold parallels with music education.

In retrospect, almost every century has left its mark in the study of music in shaping attitudes toward it. Music, being no material substance, always occupied the minds of scholars. Numerous treatises attempts to study in the context of the exact sciences, proof of this. At a time when science has generally been on the stage of development at the same time allowing scientists to study music, and astronomy, medicine, mathematics, traced its bright educational focus. The missionary task is manifested in an attempt to comprehensive presentation of theoretical and aesthetic aspects

\section{Central Asia Science of Music}

In the future, the heyday of the classical poetry of the East, the expansion of the coverage zones of

Saida Kasymhodjaeva, Ph.D., associate professor, Department of History of music and critisizm, The State Conservatory of Uzbekistan. 
theological sciences influence, loaded thought about music in a deep philosophical path. Education of the senses, morality, was given the utmost importance. The science of music of this period meets the demands of his time to satisfy the needs of the society.

The crisis of the science of music, emerging in the early 19th century, at the end of the century was their full rejection of theory and practice. In the arguments dating from this period, dominated by the scholastic ideas on the subject of music, have little to do with its domestic and aesthetic use. End of the century was characterized by the fact that any problems, including problems related to music were discussed only in the theological sphere. So the question of the role and importance of music in society goes something along the following lines: "As far as we endure the Sharia in relation to music?". This issue results in a flood of articles in newspapers and magazines. For example, in the newspaper "Al Isloh" for several years conducted fairly violent altercation between prominent members of the intelligence. The amplitude of the findings range from complete denial of music (Fazul Vahob Kari “Al Isloh" number 21 in 1915, Basil "Sharia Islomov”), through a reserved indifference (Mulla Ortikov "Al Isloh" number 2 in 1915), up to a condescending, passive tolerance (Ashurali Zahir "Al Isloh" 1916 number 2). With all the polarity of views, above their opponents position is based solely quotations from the Quran and Hadith. By the way, it should be noted that the authors did not specify precisely which areas or genres of music there is a dispute. About that what today is called home-mass music? Or is it the maqom? Most likely, the first of the music played on holidays—-weddings in tea houses and in places where the masses...

Maqoms widely known at the time culture sufficiently elitist and given that its principal place of escalation Palace of padishahs, it becomes clear that hardly anyone could afford to harsh judgments against them. Although this period and is characterized by an unprecedented flowering of bayaz creation-edition maqoms poetic texts, but they relate more to poetry than to music. During this period, intellectuals do not care about ideology of world masses. Hand-written treatises and articles in the newspapers about the music were written and challenged in their closed circle. In general, in society there was the passive contemplation. Attitude to music is seen as part of a personal self-help, religious humility, acceptance of a pre-existing world order, a perfect rejection of an active business.

\section{Music Science in the 20th Century}

At the turn of the 19th-20th centuries in Central Asia emerging movement, later named "Marifat" ("Enlightenment"), whose members advocate humanistic ideals. Around the same time, among the Volga and Crimean Tatars unfold movement "Dzhadism" at the beginning of the 20th century, widespread and in Turkestan. Critical mass was related to music, preserved in the future, it was picked up by dzhadits. But, unlike his predecessors, dzhadits tried to find a way out of that situation (Abdullah Avloniy "Madaniyatimiz Tulkinlari"- "Waves of our culture"). Without breaking with religious orientation, local dzhadids, propose to replace in schooling Arabic and Persian native-Uzbek. Among their demands-cleaning the Turkic language from Arabic and Persian influence, opening new business schools (secular) of the sample to create a national culture and the arts: theater organization, publication of newspapers, magazines and literature in their native language. Dzhadids desire in language, entailed a total re-evaluation of the place and importance of Arabic and Persian languages, and, consequently, and cultures. Comparison of Turkish and Arab-Persian began attempts to identify their interaction and identity, aroused a keen interest in Russian culture. It is to this period that the first edition of collections of songs (only texts) by Hamza and Khurshid, high development of bayaz art 
(collections of poetic texts of traditional vocal music), as well as the appearance of the first articles deals with music problems in newspapers and magazines. But, by at the early of 20th century, in the dzhadid movement, gradually planned split. Opinions are polarized, especially in relation caused by consistent rejection of that part of the national culture, to which, in particular, "Shashmақоm". Therefore, since 1919 in Uzbekistan develops its activities representative, intellectually and socially influential organization "Chigatoy Gurung" ("Chigatays conversation"), to unite the largest Uzbek scientists and culture of the period. Along with the problems of language, literature, spelling, attention was paid to the national music and its comprehension. With all the variety and even contradictions of these movements, they certainly share one thing - namely, an increased interest in Uzbek culture. The main content of their ideological and artistic and scientific creativity was expressed in stressed patriotic, nationally specific self-expression. Naturally, in that period, the attention of the local intelligently enlightened minds dwells on the problem of collecting, recording, and pre-ordering of the rich spiritual and in particular music, heritage of the Uzbek people. Educating the younger generation of the best examples of musical heritage, it was the discovery made by educators. The idea of A.Fitrat - about dosage and system familiarization mass audience maqoms culture, and further cultivation of taste and culture of the people on this basis, we can see the result of long-term observations.

And only the 20th century, with its pronounced rational direction associated with the practice of scientific research. Starting with "Enlightenment" every scientific work became a textbook, any scientific idea embodied in life as new genres, schools, higher schools of music education. The main content of their ideological and artistic and scientific creativity was expressed emphatically patriotic, national certain self-expression. Naturally, in that period, the attention of the enlightened minds of the local intelligentsia was pointed at the problem of collecting, recording, and pre-ordering of the rich spiritual, and in particular music, heritage of the Uzbek people.

At the organization and implementation of the first folk expeditions in the early 20's - the Ferghana valley, Khorezm, Bukhara in the desired result has been achieved. Based on historical data, we can safely conclude that these activities, gathering diverse material on the archeology, ethnology and philology in matters relating to the science of music at an impasse. We found that, despite attracting huge intellectual and material resources, the case for recording music at first, then fixing the poetic texts has not moved. Even in later editions- “Ashulalar" by Zafari (1926a), "Dostonlar" by Elbek (1929), where the collected material was first scientifically processed, systematized, the musical fixation was absent. This, of course, could not meet the demands of the time. In this situation, it became very positive involvement in the case of European scientists. The problem was formulated quite clearly: "Without European knowledge, we are powerless" (Fitrat, 1927).

Conflicting ideas appeared at the beginning of the 20th century, the contrasts of reality were constantly invaded in thought of music, creating the polarization of views. Paphos of controversies focused essentially around two main issues: "What is a Turkic music? What is its place and significance in the context of the eastern and wider-world music?" So, in a stormy debate was born Fitrat holistic concept of "classical Uzbek music".

This formulation of the problem has led to a significant impact; traditional forms of learning music were subjected to rethink. The priority was chosen path of development of European methods of musicology. In academic writings of Fitrat, Zafari, Rahmanov, and Harratov (have a direct impact on Mironov, Uspensky, and Romanovskaya) was already clearly through the features of innovation. 


\section{Contemporary Process}

In the context of nearly a century of development of the Uzbekistan musicology, scientific achievements of that period seem rather modest. However, it should be noted that the range of the main problems, which are further elaborated in musicology, particularly in the musical-oriental direction was undoubtedly already indicated in those years. However, further development of socio-cultural and political processes directed musicology at the new channels, many of whom did not survive the test of time.

To date, the science of music has evolved so much on what grew out of it and separated into clearly separate spheres with their problems, trends, directions: music theory, music history, ethnomusicology, music philosophy, and there are also a musical orientalism and gaining momentum music source study in Uzbekistan. And it should be noted that each of these areas has its incarnation materialized in the form of faculties, departments in the conservatory. The development of new standards, new plans, programs, new courses as an integral process of development of these sciences in general.

\section{Conclusion}

The process of music education, responsive to the demands of modernity, is enriched with new forms and opportunities with a wide range of audience. The very essence of music, as a phenomenon, its focus on the audience brings to life the emergence of new forms of musical contact. An example of this is the Department of the Estrada, formed during the years of independence, the department of "sound engineering and computer science" opened a few years ago. However, in my opinion, to date, there has been a certain tendency: the science of music in general and music education in particular, evolving and expanding more and more becoming the prerogative of specialists in their profile. Excellence, widely welcomed in all areas of activity, in our case, and has feedback. Therefore, the scope of the interests of the conservatory is not just limited to its students. With numerous scientific and creative contacts within the Republic, and far beyond the activities of the State Conservatory of Uzbekistan aims to nurture the artistic and aesthetic taste of a wide range of young people and enlighten them as to the national and universal cultural values.

\section{References}

Avloniy, A. (2006). Waves of culture. Tashkent: Gafur Gulam.

Changi, D. A. (1963). Treatise of music. Moscow: Music.

Daukeyeva, S. (2002). The Philosophy of music by Abu Nasr Muhammad al-Farabi. Alma-Aty: Atamura.

Elbek. (1929). Dostonlar. Tashkent: Maorif va okituvchi.

Fitrat, A. (1927). Uzbek classic music and its history. Tashkent: Maorif va okituvchi.

Jami, A. (1960). Treatise of music. Tashkent: Music.

Matyakubov, O. (2013). Bukhara Shashmakom. Tashkent: Music.

Matyakubov, O. (2013). The history and theoretical basis of Khorezmian tanbur notation. Tashkent: Music.

Zafari, G. (1926a). Ashulalar. Tashkent: Maorif va okituvchi.

Zafari, G. (1926b). Children music. Tashkent: Maorif va okituvchi. 